\title{
Label-Free Spectral Imaging Unveils Biochemical Mechanisms of Low-Level Laser Therapy on Spinal Cord Injury
}

\author{
Yuze Gong ${ }^{a, b} \quad$ Shuang Wang ${ }^{b}$ Zhuowen Liang ${ }^{c}$ Zhe Wang \\ Xu Zhang ${ }^{a, b}$ Jie Li ${ }^{a, b}$ Jiwei Song ${ }^{c, d}$ Xueyu Huc Kaige Wang ${ }^{b}$ \\ Qingli He $\mathrm{a}^{\mathrm{a}}$ Jintao Bai ${ }^{\mathrm{a}, \mathrm{b}}$
}

aInstitute of Photonics and Photon-Technology, The cultivation base of the state key laboratory of optoelectronic technology and functional materials co-constructed by Ministry of Education and Shaanxi Province, Northwest University, Xi'an, ${ }^{b}$ Department of Physics, Northwest University, Xi'an, 'Department of Orthopaedics, Xijing Hospital, Fourth Military Medical University, Xi'an, ${ }^{d}$ Department of Orthopaedics, Chinese people's Liberation Army 513 Hospital, Lanzhou, China

\section{Key Words}

Confocal Raman • Microspectral Imaging • Low-level Laser Therapy • Spinal Cord Injury • Photobiological Effects • Pathobiological Analysis

\begin{abstract}
:
Background/Aims: Low-level laser therapy (LLLT) leads to complex photochemical responses during the healing process of spinal cord injury (SCI). Confocal Raman Microspectral Imaging (in combination with multivariate analysis) was adopted to illustrate the underlying biochemical mechanisms of LLLT treatment on a SCI rat model. Methods: Using transversal tissue sections, the Raman spectra can identify areas neighboring the injury site, glial scar, cavity, and unharmed white matter, as well as their correlated cellular alterations, such as demyelination and up-regulation of chondroitin sulfate proteoglycans (CSPGs). Multivariate data analysis methods are used to depict the underlying therapeutic effects by highlighting the detailed content and distribution variations of the biochemical constituents. Results: It is confirmed that photon-tissue interactions might lead to a decay of the inhibitory response to remyelination by suppressing CSPG expression, as also morphologically demonstrated by reduced glial scar and cavity areas. An inter-group comparison semi-quantitatively confirms changes in lipids, phosphatidic acid, CSPGs, and cholesterol during SCI and its LLLT treatment, paving the way for in vitro and in vivo understanding of the biochemical changes accompanying pathobiological SCI events. Conclusion: The achieved results in this work not only have once again proved the well-known cellular mechanisms of SCI, but further illustrate the underlying biochemical variability during LLLT treatment, which provide a sound basis for developing real-time Raman methodologies to monitor the efficacy of the SCI LLLT treatment.
\end{abstract}




\section{Introduction}

Spinal cord injuries (SCIs) are devastating events that often result in permanent neurological deficits [1]. The final impairments of SCI result from the joint effect of two distinct mechanisms: the primary and secondary lesions. The primary lesion is the mechanical injury itself, and operates in the form of acute structural and physiological disruption of axons, nerve cell damage and blood vessel ruptures [2]. The secondary lesion operates through induced biochemical changes and a cascade of events involving inflammatory and cytotoxic processes and the degeneration of neural tissue. This cascade of biological events, triggered by the initial trauma and mediated in part by the immune response, occurs immediately after injury and may persist for months to years, which magnifies the neurologic impairment and prevents neurologic recovery $[3,4]$. Much effort is presently being put into various avenues for the treatment of spinal cord injuries, including the use of anti-inflammatory drugs [5], X-irradiation [6, 7], elimination of inhibitory factors in the spinal cord [8-10], provision of neurotrophic factors $[11,12]$, cell transplantation, and tissue engineering [13-16]. However, there is currently no cure allowing the total recovery and normalization of the sensory or motor deficits resulting from injury.

Low-level laser therapy (LLLT), also known as photobiomodulation (PBM), is an effective treatment for cutaneous wounds, relieving the pain and promoting peripheral nerve regeneration [17-19]. This technique involves exposing cells or tissue to low level of red and near-infrared light using a coherent laser or light emitting diodes, and is referred to as "low level" because its power density is lower than those needed to produce tissue heating [5-20]. A large body of evidence has already demonstrated the effects of LLLT on the regeneration of traumatized nerves by increasing the cellular metabolism and DNA and RNA synthesis in the cell nucleus [21, 22], accelerating the production and/or inhibiting the chemical mediators involved in the inflammatory process [20], motivating the immune system $[5,23,24]$, stimulating fibroblast proliferation [25, 26], decreasing edema [25-27], and activating microcirculation and capillary formation [28]. In subsequent work, LLLT can alter the microglial phenotype across this spectrum in a dose-dependent manner, which is important for understanding the LLLT mechanisms [29]. Ando et al. reported that rats treated with an $808 \mathrm{~nm}$ laser whose polarization was parallel to the spinal direction showed a significantly faster recovery of locomotor function than the rats treated with perpendicular polarization [30]. Rochkind et al. demonstrated that the transplantation of embryonal spinal cord nerve cells followed by $780 \mathrm{~nm}$ laser irradiation enhanced axonal sprouting and spinal cord repair in a completely transected rat SCI model [31].

Raman spectroscopy (RS) is a unique analytic probe for molecular vibration, and may provide specific information about the structure and conformation of biomolecular constituents in tissue samples [32]. As one of the Raman-based imaging mechanisms, confocal Raman microspectral imaging (CRMI) enables high-contrast, high-resolution imaging of molecular composition and structure without the need for introducing any external labels or dyes $[33,34]$. The chemical nature of the sampling area can be evaluated from selected Raman bands of the individual spectra obtained at every scanning point of the sample when the discrete spectroscopic information is obtained from a unique spatial location [35]. Saxena et al. explored the possibility of using RS to study the demyelination and chondroitin sulfate proteoglycans (CSPGs) up-regulation after SCI [36]. Wang et al. interpreted the biochemical specificity of spinal cord tissue from human and rat by using CRMI $[37,38]$. Ruberto further provided evidence that Raman spectral variations could be discernable during the chondroitinase ABC treatment of SCI [39]. Galli et al. assessed the ability of Fourier transform infrared spectroscopy and spontaneous RS to generate contrast data between the normal and altered regions at the molecular level in a SCI rat model [40]. They also applied RS to characterize the morphochemical properties of surgically induced spinal cord injuries in rats that received an implant of soft unfunctionalized alginate hydrogel [41]. Additionally, coherent anti-Stokes RS was also used to visualize myelin sheets in normal spinal cords and to study the myelin sheet swelling and myelin sheet retraction and repair after SCI $[40,42]$.

In this work, we aim at understanding the therapeutic mechanisms of low-level laser treatment on SCI, using CRMI in combination with multivariate analysis methods. The animal model chosen for this work was the rat with moderate contusion injuries; the injury sites were directly irradiated with an $810 \mathrm{~nm}$ diode laser immediately after injury and, 
afterward, daily for 14 consecutive days. Using transversal tissue sections, comparative spectroscopic investigations were used to determine the pathobiological distinctions by identifying significant spectral variations among the different experimental groups: the health group, the 14-day post-injury (14 DPI) group, and the 14 day laser-treated (14 DLT) group. $K$-mean cluster analysis (KCA), which is one type of multivariate analysis algorithm, was conducted to highlight some minute and important the biochemical composition and/or structural changes observed after tissue injury and low-level laser treatment. For more complete overview of the potential laser-induced pathobiological changes, principal component analysis (PCA) was further conducted, to extract the biochemical composition properties from the acquired spectral dataset. The observed spectral phenomena not only have once again proved the well-known cellular mechanisms of SCI, but further illustrate the underlying biochemical variability during LLLT treatment, which provide a sound basis for our future work on real-time investigation of in vivo low-level laser therapy of SCIs.

\section{Materials and Methods}

\section{Spinal cord injury model}

The protocol used in this study was approved by the Animal Care Ethics Committee of the Fourth Military Medical University, Shaanxi, China. Eighteen female Sprague Dawley rats weighing 270-350 g were used and divided into the Health $(n=6)$, the 14-day post-injury (14 DPI) group $(n=6)$, and the 14 day lasertreated (14 DLT) group $(n=6)$ used in this study. In the health group, the T9 spinal cord segments of the rats were directly sampled and prepared for cross sectioning. A bilateral compression SCI model was performed on the animals of the 14 DPI and 14 DLT groups with a pair of forceps (Fine Science Tools, Germany). The forceps were modified by adding a metal spacer between the blades, so as to achieve a $0.5 \mathrm{~mm}$ gap when entirely closed. The animals were anesthetized with sodium pentobarbital $(1 \%, 50 \mathrm{mg} / \mathrm{kg})$ and put on a homothermal blanket. A sagittal incision was then made at T8-T10, and a laminectomy was performed at the T9 segment. The blades of the modified forceps were placed bilaterally to the T9 spinal cord segment, were fully closed for 20 seconds, and then released. Immediately after inflicting the contusion in the spinal cord, the animals in the 14 DLT group were transcutaneously treated by 810 -nm low-level laser irradiation. A bladder squeeze was performed twice daily until the animals recovered spontaneous urination. After 14 days of post-injury, the animals in both 14 DPI and 14 DLT groups were sacrificed and the injured spinal cord tissues were collected for histological and spectral analysis.

\section{LLLT protocol}

The laser irradiation process was conducted according to the work of Kimberly et al. [2] and previous study in our group [3]. Briefly, after the rats were slightly anesthetized, a continuous $810 \mathrm{~nm}$ diode laser (MW-GX-808, Lei Shi Optoelectronics Co., Ltd. China) was transcutaneously irradiated at the lesion site. The output power of laser was $150 \mathrm{~mW}$, and the collimated light spot had a diameter about $0.62 \mathrm{~cm}$, resulting in a power density of $500 \mathrm{~mW} / \mathrm{cm}^{2}$. The rats in 14 DLT group received once-daily laser therapy, which lasted for 50 minutes at a time, continuously, from day 1 to day 14. The dosage applied to the surface of the skin was $1500 \mathrm{~J} / \mathrm{cm}^{2}$ per day (Dosage=[energy $\times$ time] $/$ treatment area; $0.45 \mathrm{~W} / \mathrm{cm}^{2}, 450 \mathrm{~J}$ ) [5]. During treatment, the light spot was centered on the skin directly above the location of the spinal cord hemisection, with the expectation that spot size would spread as it progressed through the tissue, while penetrate enough depth into tissue, as it testified by reference $[5,30]$. Besides that, the polarization direction of radiation source was parallel to the spinal cord direction for achieving better light penetration depth and therapeutic efficacy, which have been clarified by the work of Takahiro, et al. [30]. All laser treatments were applied in dark, and no adverse events were noted at the illumination site on skin surface during treatment.

Sample preparation and histological analysis

The rats were perfusion-fixed using 4\% paraformaldehyde (PFA) in phosphate buffered saline. The spinal cord was removed and postfixed in PFA for $24 \mathrm{~h}$ at $4^{\circ} \mathrm{C}$. Dehydration in rising sucrose concentration ( $10 \%$ for $24 \mathrm{~h}$ and $30 \%$ for $24 \mathrm{~h}$ ) was then followed by embedding the isolated spinal cords in tissue-freezing medium. The samples were snap-frozen in liquid nitrogen and stored at $-80^{\circ} \mathrm{C}$. Transversal sections of 20 $\mu \mathrm{m}$ thickness were prepared on gold-coated slides for spectroscopic analysis (BioGold $₫$ 63479-AS, Electron Microscopy Sciences, USA), and exhibited a good spectral signal quality because of the substrate's low background signal contribution and reflective properties compared to transparent quartz substrates [37, 38]. Consecutive 20 - $\mu \mathrm{m}$ thick sections were prepared on glass slides and hematoxylin and eosin (H\&E) stained to provide direct comparison of the spectroscopic imaging results to histopathology. The sections 


\section{Cellular Physiology Cell Physiol Biochem 2018;49:1168-1183

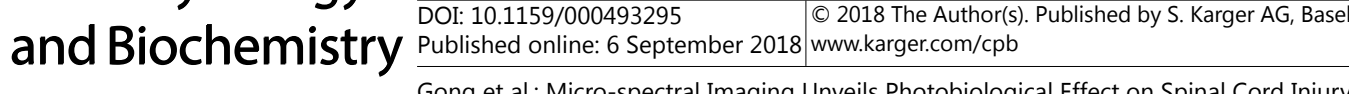

were washed in distilled water and incubated in Meyer's hematoxylin/hemalum for 3 min. After having been washed in aqua dest, the tissue was briefly distained in HCl-ethanol. Washing using tap water for 5 min was followed by 3 min of staining in eosin (1\% eosin G in $80 \%$ ethanol). The sections were dehydrated with rising ethanol concentrations, cleared in xylene, and cover-slipped using DePex (Sigma-Aldrich, United States). For histologic evaluation of the cross sections at the lesion epicenter, the irregular cavity shapes in the generated sub-cluster images were detected, and their area was calculated using Matlab image processing functions (The Mathworks, Inc., United States).

\section{Confocal Raman spectroscopy}

Raman spectra were acquired by an Alpha 500R confocal Raman microscopy system (WITec GmbH, Germany) coupled with a helium-neon (He-Ne) continuous $633 \mathrm{~nm}$ laser (35 mW at $633 \mathrm{~nm}$, Research Electro-Optics, Inc., USA). After passing through a holographic $633 \mathrm{~nm}$ bandpass filter, the excitation laser beam was collimated into a $100 \times$ objective lens (NA = 1.25, EC Epiplan-NEOFLUAR, Zeiss, Germany) for spectral measurements. The sample was placed on a multi-axis piezo scanning stage (P-524K081, PI GmbH, Germany). Beneath that, an additional motorized $x y$ stage was connected to expand the scanning range from $200 \times 200 \mu \mathrm{m}^{2}$ to $150 \times 150 \mathrm{~mm}^{2}$, which is ideal for large-area Raman imaging. The spectral signal was recorded by a spectrometer (UHTS300, WITec GmbH, Germany) incorporating a $600 \mathrm{~mm}^{-1}$ grating blazed at $500 \mathrm{~nm}$ with a back-illuminated deep-depletion charge coupled device camera (Du401A-BR-DD-352, Andor Technology, UK) working at $-60^{\circ} \mathrm{C}$. Video images of the complete tissue sample could be generated by stitching multiple microscopy graphs in $300 \times 300$ pixels with a $20 \times$ objective (NA = 0.4, Epiplan-Neofluar, Zeiss, Germany). Raman hyperspectral datasets were continuously accumulated with a $63 \times$ objective (NA $=0.85, \mathrm{~N}$-Achroplan, Zeiss, Germany) at a speed of 2 seconds per pixel in the scanning range of $800 \times 1000$ $\mu \mathrm{m}^{2}(160 \times 200$ pixels $)$ for the health and 14 DPI group, and of $1 \times 1 \mathrm{~mm}^{2}$ (200 $\times 200$ pixels $)$ for 14 DLT group on $x y$ plane.

\section{Spectral data analysis}

The WITec Project FOUR (WITec GmbH, Germany) was used to preprocess all the obtained datasets for band range selection, cosmic ray removal, spectra smoothing, and background subtraction. All the Raman spectra were normalized by the method of area-under-the-curve between $400 \mathrm{~cm}^{-1}$ and $1800 \mathrm{~cm}^{-1}$ for minimizing the effect due to sample and instrument variabilities such as sample inhomogeneity and excitation light intensity drift. After interpreting the spectral features, K-mean clustering algorithm-one of the used multivariate analysis algorithms - was applied for automatic identification and visualization of the chemical components. The cluster membership information was plotted as a color-coded image, and the average spectrum of each cluster was adopted to detect variations in the Raman band positions and/or intensities among the different regions. After that, principal component analysis (PCA) was further applied, to decrease the amount of preprocessed data and thus enable further analyses. PCA converts a set of possibly correlated variables into a set of linearly uncorrelated variables, the principal components (PCs). The first PC accounts for as much of the variance in the data as possible, and each succeeding PC has the highest variance possible under the constraint of being uncorrelated with the preceding components. In the present work, only the first three obtained PCs were considered when interpreting the tissue biochemical constitutions.

\section{Results}

\section{Histologic evaluation}

A typical microscopic pathological image of the spinal cord's transverse section from un-injured and un-treated rats in health group is shown in Fig. 1a, in which the white matter can be seen to be arranged around a butterfly-shaped area of gray matter. The gray matter on both sides is connected across the midline by the dorsal gray commissure and below the white commissure. Because of the development of scar tissue, the contusion SCI tissue from 14 DPI group (Fig. 1b) featured a central haemorrhagic necrosis that spread radially and rostrocaudally, resulting in an ellipsoidal, loculated cystic cavity [43]. Typical morphological cavity characteristics could also be observed in the sample from 14 DLT group (Fig. 1c). For both histological images of Fig. 1b and 1c, cavity areas in 14 DPI and 14 DLT groups were manually outlined with blue curves. After a visual comparison between the area of curves, it could be realized that cavity areas for the rats in 14 DLT group was significantly smaller than those for the rats in 14 DPI group, which showed that laser irradiation led to reduced 


\section{Cellular Physiology

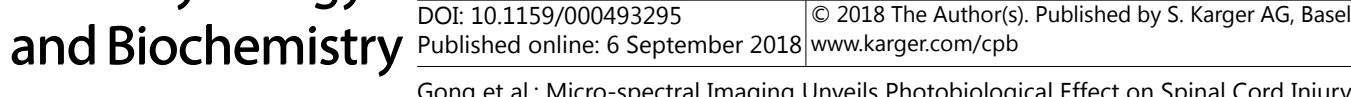

formation of glial scar and cavity. Also, the contraction state of the injured tissue in 14 DPI group has been greatly improved after laser therapy.

\section{Featured Raman spectra of SCI and LLLT-SCI}

A comparison among the mean Raman spectra of health, 14 DPI, and 14 DLT groups was performed according to histological evaluations, as shown in Fig. 2. During the experiment, the featured spectra were measured randomly from 10 to 20 spots of the ventral horn in Health group, the tissue around cavity in 14 DPI and in 14 DLT groups. The featured spectra in each group was presented by the average spectra from different samples. The spectra variations among tested samples was small and some systematic characteristics could be perceived around 510, 540, 617, 643, 719, 750, 860, 939, 1071, 1137, 1300, 1343, 1445, 1554,1630 , and $1668 \mathrm{~cm}^{-1}$, whose biochemical assignments are listed in Table 1.

Given that both lipids and protein are critical to tissue protection and information transmission, the three lipid bands, $1300 \mathrm{~cm}^{-1}\left[\tau_{i p}\left(\mathrm{CH}_{2}\right)\right.$ twisting and wagging], $1445 \mathrm{~cm}^{-1}$ $\left(\mathrm{CH}_{2} / \mathrm{CH}_{3}\right.$ scissoring), and $1668 \mathrm{~cm}^{-1}$ [Amide $\mathrm{I} / \mathrm{v}(\mathrm{C}=\mathrm{C})$ stretching], were very prominent in all spectra, as were also the protein Amide III bands at $943 \mathrm{~cm}^{-1}$ and $1250 \mathrm{~cm}^{-1}$, as well as the Amide I bands at $1630 \mathrm{~cm}^{-1}$. A non-negligible fact that $1445 \mathrm{~cm}^{-1}$ Raman peaks in the health spinal cord tissue are shifted to the higher wavenumber $\left(1450 \mathrm{~cm}^{-1}\right)$ in 14 DPI and 14 DLT groups, which is a wavenumber characteristic for $\mathrm{CH}_{2}$ deformation from lipids and proteins [44]. Meanwhile, the band at $1668 \mathrm{~cm}^{-1}$ is a feature related to the cholesterol fragment, i.e. to the $\mathrm{C}=\mathrm{C}$ stretching vibration in $14 \mathrm{DPI}$ and 14 DLT groups, which showed a small shift toward lower wavenumbers compared with free cholesterol in health group [45].

The $510 \mathrm{~cm}^{-1}$ Raman band could be attributed to CSPG aggregation, which acts both as a physical barrier-by means of sheer concentration-and as a chemical barrier to axon regeneration [46]. As observed in Fig. 2b and 2c, when compared to the SCI tissue, the LLLT tissue around the injury site shows a decrease in the intensity of both CSPG aggregation peaks ( 510 and $540 \mathrm{~cm}^{-1}$ ), and a significant increase in the peak intensity at $860 \mathrm{~cm}^{-1}$, which is attributed to the $v(\mathrm{C}=0)$ of phosphatidic acid, the primary component of the myelin sheath and cell membranes [47]. The intensity variations of the CSPG and phosphatidic acid peaks indicated that the low-level laser irradiation after SCI reduces the formation of glial scar and promotes the growth of the myelin sheath and axon by the transportation of phospholipids.

Except for that, CSPGs and glycosaminoglycan (GAG) were also observed at the $\delta \mathrm{CH}\left(\mathrm{CH}_{2}\right)$ peaks at $1343 \mathrm{~cm}^{-1}$, whereas the 890 $\mathrm{cm}^{-1}$ bands are attributed to stretching vibrations of the $\mathrm{C}_{(1)}-\mathrm{H}$ bonds in $\beta$-anomers. Clear vibrations were also evident in regions assigned to glucose and its derivatives (1070 and $1137 \mathrm{~cm}^{-1}$ ), attributed to the vibrations of $v(\mathrm{C}-\mathrm{OH})$ and $v(\mathrm{C}-\mathrm{H})$, respectively. The $913 \mathrm{~cm}^{-1}$ Raman peaks were attributed to deformation vibrations of $\mathrm{v}(\mathrm{C}-\mathrm{OH})$, corresponding to monosaccharides, including

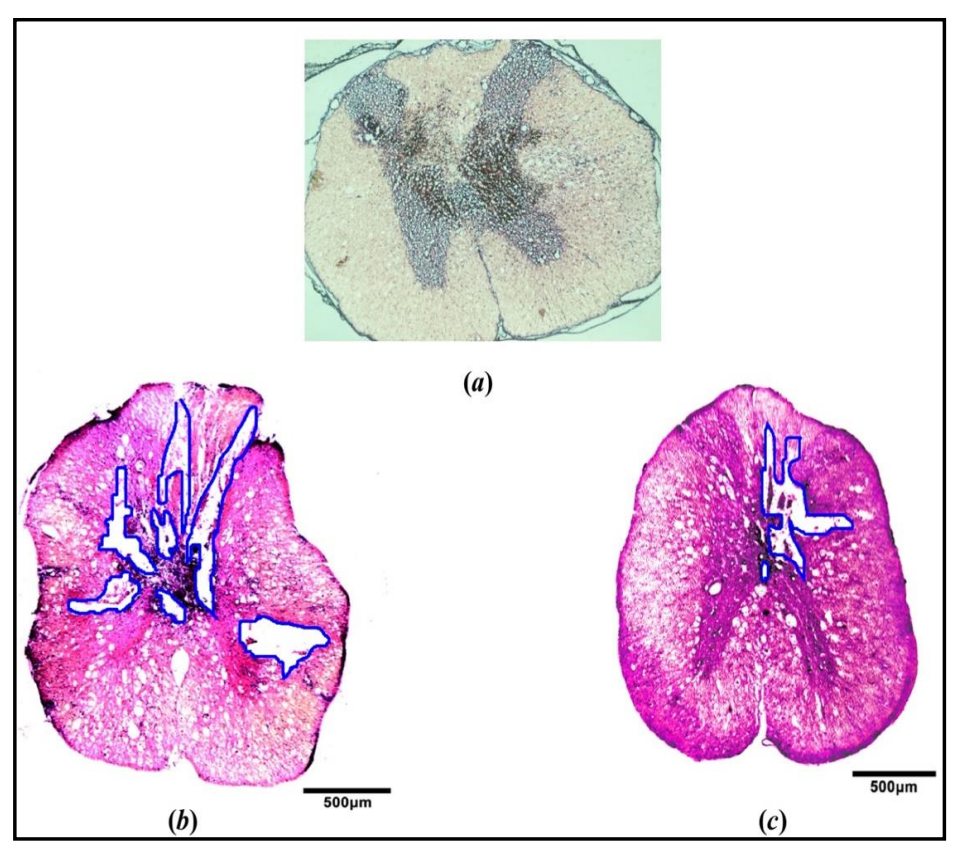

Fig. 1. The microphotograph of H\&E stained rat spinal cord tissue section with $500 \mu \mathrm{m}$ scale bar: (a) Tissue from healthy/uninjured rat in Health group; (b) Tissue from SCI rat in 14 days post-injury group (14 DPI); (c) Tissue from laser treated SCI rat in 14 days laser treated group (14 DLT). The cavity areas in 14 DPI and 14 DLT groups were manually outlined with blue curves. 
Fig. 2. Featured spectra of the ventral horn from ex vivo spinal cord tissue in the Health group in green (a), tissue around cavity in 14 DPI group in blue (b) and 14 DLT groups in red (c). The spectral intensities are normalized to their respective areas under the curves between $400 \mathrm{~cm}^{-1}$ and $1800 \mathrm{~cm}^{-1}$.

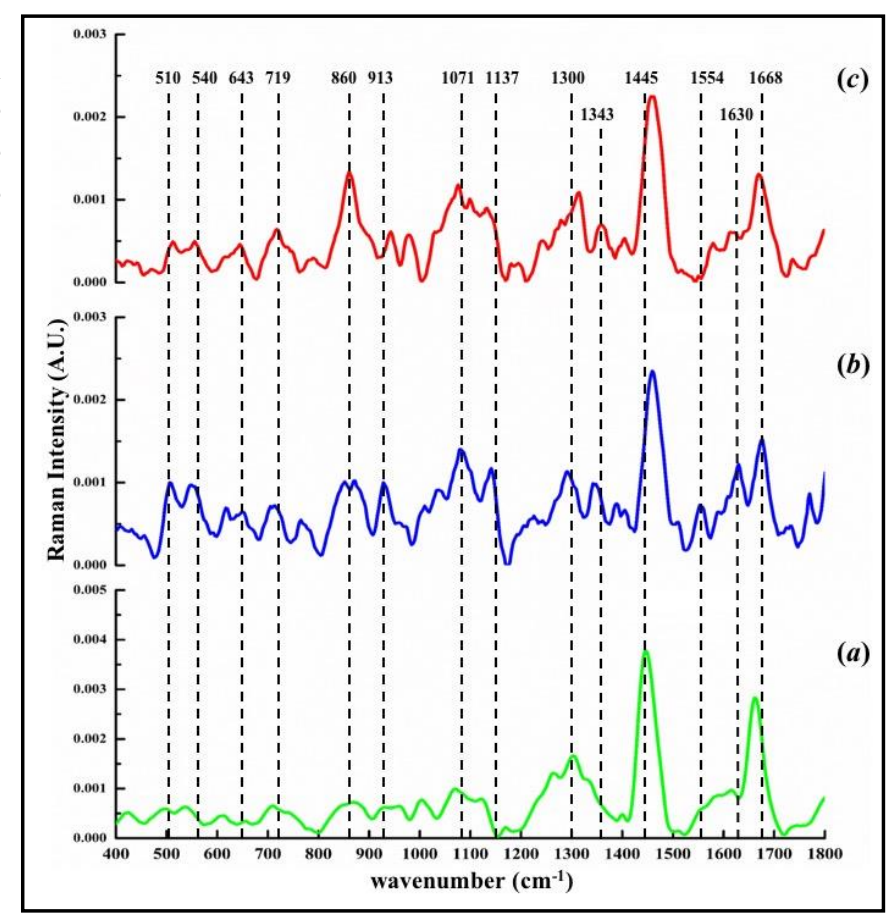

Table 1. Peak assignments for the spectra of the rat spinal cord tissue. Greek letters denote the type of vibrational mode $\left(v=\right.$ stretching, $v_{\text {asym }}=$ asymmetry stretching, $\delta=$ bending, $\tau_{\mathrm{ip}}=$ twisting and wagging in plane, $\alpha=$ scissoring)

\begin{tabular}{|c|c|c|c|}
\hline Band position $\left(\mathrm{cm}^{1}\right)$ & Vibrational Group and Mode & Biochemical Assignment & References \\
\hline 510 & $v(\mathrm{C}-\mathrm{OH})$ & CSPG Aggregation & [36] \\
\hline 540 & $v(\mathrm{C}-\mathrm{OH})$ & CSPG Aggregation & [39] \\
\hline 617 & $v(\mathrm{C}-\mathrm{OH})$ & GAGs & [36] \\
\hline 643 & $\delta(\mathrm{C}-\mathrm{C})$ twisting, $\mathrm{C}-\mathrm{S}$ & Tyrosine & [39] \\
\hline 700 & Sterol ring & Cholesterol & {$[36,39,60]$} \\
\hline 719 & $v\left(\mathrm{~N}^{+}\left(\mathrm{CH}_{3}\right)_{3}\right) \& v\left(\mathrm{~N}^{+}\left(\mathrm{CH}_{3}\right)_{3}\right)$ stretching & Choline in Phosphatidylcholine & [61] \\
\hline 750 & $\begin{array}{c}\mathrm{v}(\text { pyr breathing); } \\
\mathrm{v}\left(\mathrm{C}_{\alpha} \mathrm{C}_{\beta}\right)\end{array}$ & Heme & [62] \\
\hline 860 & $v(C=0)$ & Phosphatidic acid & [61] \\
\hline 890 & $\mathrm{C}_{(1)-\mathrm{H}}$ & $\beta$-anomers & [39] \\
\hline 913 & $v(\mathrm{C}-\mathrm{OH})$ & $\begin{array}{l}\text { Monosaccharides } \\
\text { (glucose\& ribose) }\end{array}$ & [39] \\
\hline 943 & $\begin{array}{l}v(C-C) \text { Stretching } \\
\text { Amide III }\end{array}$ & Protein & [63] \\
\hline 1071 & $v(\mathrm{C}-\mathrm{OH})$ & Glucose & [52] \\
\hline 1137 & $v(\mathrm{C}-\mathrm{OH}), \mathrm{v}(\mathrm{C}-\mathrm{H})$ & Glucose derivatives & [36] \\
\hline 1250 & Amide III & Protein & [60] \\
\hline 1300 & $\tau_{\text {ip }}\left(\mathrm{CH}_{2}\right)$ twisting and wagging & Lipids & {$[36,3960]$} \\
\hline 1343 & $\delta \mathrm{C}-\mathrm{H}\left(\mathrm{CH}_{2}\right)$ & GAGs & [52] \\
\hline 1445 & $\alpha\left(\mathrm{CH}_{2} / \mathrm{CH}_{3}\right)$ & Lipids & {$[45,58]$} \\
\hline 1554 & $\mathrm{~V}_{\text {asym }}\left(\mathrm{C}_{\alpha} \mathrm{C}_{\mathrm{m}}\right)$ & Heme & {$[36,60]$} \\
\hline 1630 & Protein amide I $\beta$-structure & Proteins & {$[48,49]$} \\
\hline 1668 & Amide $I / v(C=C)$ stretching & Proteins/Lipids & {$[44,45]$} \\
\hline
\end{tabular}

glucose and ribose. The $1554 \mathrm{~cm}^{-1}$ peak is the common spectral feature of heme, which is attributed to the vibration of $v_{\text {asym }}\left(\mathrm{C}_{\alpha}=\mathrm{C}_{\mathrm{m}}\right)$.

Relative spectral contributions in health, 14 DPI and 14 DLT groups

For a qualitative understanding of the low-level laser therapeutic mechanism, one way ANOVA and Tukey's honest significant difference (HSD) post hoc multiple test were sequentially applied, to compare the individual peak intensities in the Health, 14 DPI, and 14 DLT groups. Remarkable variances were perceived by investigation of the spectral 
contribution of CSPGs, phosphatidic acid, cholesterol, lipids, and Amide I at 14 days after injury and/or laser treatment, as shown in Fig. 3.

The 510 and $540 \mathrm{~cm}^{-1}$ Raman bands were specifically present in the spectra of chondroitin sulfate-A and aggrecan, the unbranched polysaccharide side-chains of CSPGs. A large enhancement in both Raman peaks shown in Fig. 3a, illustrated a high expression of CSPGs as inhibiting factors for remyelination and axon regeneration both physically and chemically after SCI. After laser treatment, photon-tissue interactions might have led to a decay of the inhibitory response upon remyelination by suppressing CSPG expression. That's why a significant decrease in the CSPGs spectral contribution could be recognized in Fig. 3a.

Myelin is composed of cholesterol, phospholipids, galactolipids, and plasminogen in a molar ratio of approximately 2:2:1:1. Phosphatidic acid is the parent compound of phospholipids without an alcohol head group, which is the main component of cell membrane and myelin. Phosphatidic acid led to a major intensity increase of the peak at $860 \mathrm{~cm}^{-1}$ inside the injured tissue, shown in Fig. 3b. According to Katsuhiko's work [48], that is because many axons remained naked but intact after their myelin sheaths has been completely disintegrated around the lesion site. Such naked axons were subsequently remyelinated by mature or immature glial cells. After laser irradiation, numerous immature glial cells appeared in association with naked axons, and some of them were differentiated into oligodendrocytes forming thin myelin sheaths on naked axons. Therefore, the spectral variances of phosphatidic acid were correlated to the remyelination of oligodendrocytes, which is critical for the therapeutic effect of LLLT.

Although the cholesterol's Raman peak at $700 \mathrm{~cm}^{-1}$ overlaps with neighboring bands of Choline in Phosphatidylcholine at $719 \mathrm{~cm}^{-1}$, it exhibited a similar change with $1450 \mathrm{~cm}^{-1} \mathrm{CH}_{2}$ deformation mode after injury in Fig. $3 \mathrm{c}$ and $3 \mathrm{~d}$, corresponding to demyelination of the axons and cell death. Given that myelin is formed by wrapped oligodendroglia cell membranes and contains approximately $70 \%$ lipids and $30 \%$ proteins by weight, the demyelination process after SCI would likely reduce the $\mathrm{CH}_{2}$ vibrational modes, and lead to a dramatic intensity loss in $1450 \mathrm{~cm}^{-1}$ lipid peaks as shown in Fig. 3d, which could also be correlated to the apoptosis of the nervous tissue cells in which a certain amount of lipids is contained. A slight rise of the cholesterol and lipid concentration spectral contribution after laser therapy could be observed in Fig. 3c and 3d, indicated the increased presence of functional remyelinated axons facilitated by the laser-induced tissue response.

The $1630 \mathrm{~cm}^{-1}$ peak is more difficult to interpret from the viewpoint of protein configuration, however, according to Pedro's [49] and Zanyar's work [50], it could be ascertained that $1630 \mathrm{~cm}^{-1}$ is corresponded to protein amide I $\beta$-structure from myelin membranes. As shown in Fig. 3e, its spectral contribution increased firstly after injury, which was hypothesized to be due to inhibitory myelin debris formation in ischemic conditions post injury. And then, a decrease in its contribution, may indicate remyelination facilitated by the photobiological effects of laser irradiation followed by a decreased content of inhibitory factors.

\section{Multivariate Image}

After spectral analysis, $K$-mean clustering was applied to help visualize the biochemical variation after LLLT treatment. Different types of tissue could be identified by classifying the obtained spectral datasets into four clusters, as shown in Fig. 4. In the 14 DPI group (Fig. 4A), the brown cluster possesses a prominent spectral feature of lipid-rich white matter inside the sample. Areas neighboring the injury site (in blue color), was identified by the lipid bands at $1064,1300,1445$, and $1668 \mathrm{~cm}^{-1}$ with a small number of protein $\left(1630 \mathrm{~cm}^{-1}\right)$ and heme $\left(1578 \mathrm{~cm}^{-1}\right)$ ingredients. The red cluster was characterized by a diminished intensity of the $1445 \mathrm{~cm}^{-1}$ peak and an increased intensity of the $510 \mathrm{~cm}^{-1}$ band, which can be recognized as features of the glial scar. Meanwhile, the green cluster, with almost no spectra signal profiled, corresponds to the area where cavities formed.

The classified 14 DLT dataset is shown in Fig. 4B, in which the characteristic spectra of the brown area are found to be quite similar to that of the unharmed white matter with highest contribution of lipids in Fig. 4A. Compared with the red glial scar region, the blue area neighboring the injury site exhibited spectral features corresponding to more lipids and less saccharides such as CSPGs. In contrast, the lesion site was characterized in the sample by a decrease in the lipid-related band intensity and an increase of the CSPG-related band. Meanwhile, after laser irradiation, the CSPG bands in the lesion cluster of the LLLT group 


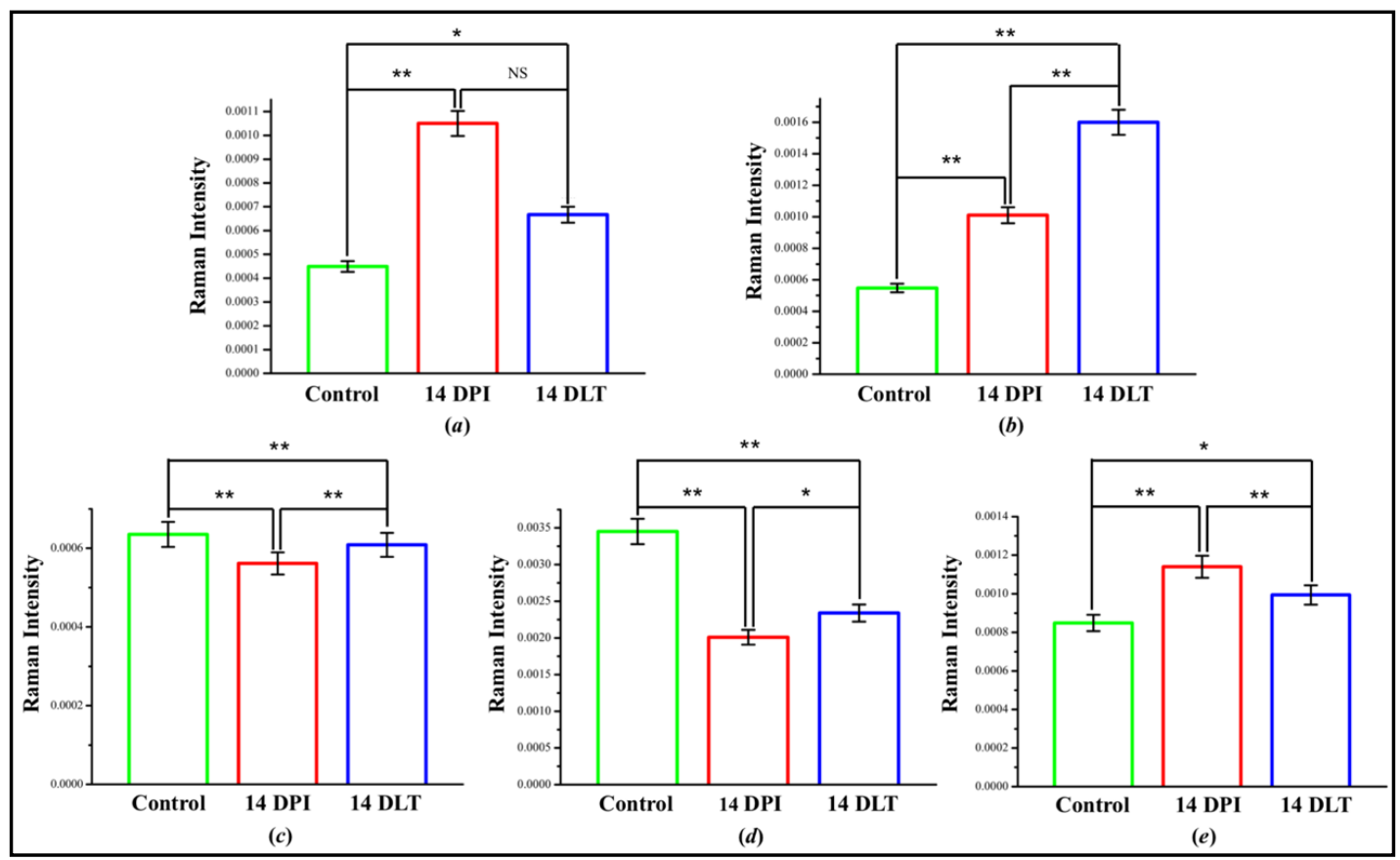

Fig. 3. Box chart displaying the relative spectral contribution of biochemical species to sampled spinal cord tissue in health group (green color), 14 DPI group (red color) and 14 DLT group (blue color). Each species was plotted as mean \pm standard deviation in (a) CSPGs $\left(510 \mathrm{~cm}^{-1}\right)$, (b) Phosphatidic acid $\left(860 \mathrm{~cm}^{-}\right.$ $\left.{ }^{1}\right)$, (c) Cholesterol $\left(700 \mathrm{~cm}^{-1}\right)$, (d) lipids $\left(1445 \mathrm{~cm}^{-1}\right)$, (e) Protein Amide I $\left(1630 \mathrm{~cm}^{-1}\right)$. One-way ANOVA was followed by Tukey's HSD post hoc multiple comparison tests. Asterisks indicate levels of significance, NS=Not Significant, ${ }^{*} \mathrm{P}<0.05,{ }^{* *} \mathrm{P}<0.01$.

exhibited a lower spectral intensity than those of the SCI group. Besides that, the tissue neighboring the injury site in the LLLT group exhibited an increased spectral intensity of the lipid peaks, especially at $1445 \mathrm{~cm}^{-1}$, indicating that the laser induced axonal regeneration and demyelination restoration.

Furthermore, the monosaccharides $\left(913\right.$ and $\left.1071 \mathrm{~cm}^{-1}\right)$ were distributed overall in the sample, while the protein $\left(943 \mathrm{~cm}^{-1}\right)$ was mainly distributed in the glial scar area (Fig. 4B). Although the green region still reveals cavity structures, its area in the LLLT group was visually smaller than that in the SCI group, indicating that laser irradiation was capable of bringing about a positive therapeutic effect by reducing the formation of glial scar and cavities, and promoting the repair of the spinal cord injury.

Fig. 5 shows the results of a quantitative analysis of the fractional area of each cluster relative to the whole sampled SCI area, based on KCA imaging in Fig. 4. After spinal injury, a series of reactive cellular processes occurs forming a cystic cavity in the region surround by the scar. In the context of neurodegeneration, formation of the glial scar leads to a progressive increase in the size of the cavitation area. So, a potential approach is to attempt to prevent the scar forming in the first place or to remove it once formed [51]. Since that, we evaluated cavity area as the most important histopathological outcome. As shown in Fig. 5d, the cavity area in green was reduced from $12.44 \%$ in the 14 DPI group to $7.47 \%$ in 14 DLT group, whereas the glial scar area in red was reduced from $30.67 \%$ in 14 DPI group to $23.04 \%$ in 14 DLT group, as shown in Fig. 5c. This demonstrates that laser irradiation can lead to reduced formation of glial scar and cavities. Although the fractional area of healthy white tissue showed little increase (see Fig. 5a), it is still interesting to find that the fractional area of tissue neighboring the injury site in blue had a sharp increase (from $46 \%$ to $58 \%$ ) after laser therapy, which indicates that the light-tissue interaction did improve the restoration of injured tissue. 
PCA

To obtain further insights into the spectral variability of the different tissue regions, a PCA was then performed on all the acquired spectra datasets. Some representative spectra loadings from 14 DPI and 14 DLT groups are shown in Fig. 6. The spectra loadings were offset for clarity, with the dotted line indicating the zero point in each case.

In the SCI group, shown in Fig. 6A, the three principal components PC1, PC2, and PC3 explained $69.8,10.2$, and $3.87 \%$ of the total variance in the data set, respectively. The first component, PC1, exhibited intense positive loadings for Raman shifts characteristic of glial scar constituents such as CSPGs (at 510 and $617 \mathrm{~cm}^{-1}$ ), and featured a peak for human dried blood at $1610 \mathrm{~cm}^{-1}$, which were attributed to $\mathrm{v}\left(\mathrm{C}_{\alpha}=\mathrm{C}_{\beta}\right)$ representing vinyl group carbons [52]. It also had some other peaks, which can be attributed to biochemical constituents such as lipids $\left(1064,1300,1445\right.$, and $\left.1668 \mathrm{~cm}^{-1}\right)$, protein $\left(1250 \mathrm{~cm}^{-1}\right)$, choline $\left(719 \mathrm{~cm}^{-1}\right)$, and glucose derivatives $\left(1137 \mathrm{~cm}^{-1}\right)$. Differentiating between glial scar and its surrounding tissue based on the spectral features of CSPGs and proteins is somewhat trivial. However, the loading image is rich in features that further contribute to the differentiation with the joint consideration of the red cluster in Fig. 4A (a). The second principal component, PC2, exhibited spectral features associated with lipids at 1070,1300,1445, and $1668 \mathrm{~cm}^{-1}$, which were close to the Raman spectra of unharmed white matter. The loading imaging of PC2 also exhibited a good correlation with the brown region in the KCA of the sample (shown in Fig. $4 \mathrm{~A}$ ). Component PC3 was rather noisy, its negative peaks at 750,1300,1445, and $1610 \mathrm{~cm}^{-1}$ are as informative as the positive ones and matched with specific features for the molecular and morphologic characterization of tissue area neighboring the injury site.

On the other hand, the components PC1, PC2, and PC3 of the 14 DLT group explained $75.1,13.78$, and $2.57 \%$ of the total variance in the dataset, respectively. As shown in Fig. 6B, PC1 displayed a mixture of positive peaks of CSPGs $\left(540 \mathrm{~cm}^{-1}\right)$, phosphatidic acid $\left(860 \mathrm{~cm}^{-1}\right)$, and lipids $\left(1064,1300,1445\right.$, and $\left.1668 \mathrm{~cm}^{-1}\right)$. Its loading image also clearly profiled the top edge of the lipid-rich white matter. PC2, which is correlated to glial scar, showed three prominent negative peaks at 1064,1445, and $1668 \mathrm{~cm}^{-1}$, while positive loadings appeared at the wavenumber for GAGs $\left(1343 \mathrm{~cm}^{-1}\right)$ and heme $\left(1589 \mathrm{~cm}^{-1}\right)$ [53]. PC3 showed near-zero loadings, profiling the cavity regions in Fig. 4B. In combination with KCA, the loading image sheds further light on the basis for differentiating the different tissue regions. However, the loadings are complex or inconclusive, requiring interpretation of the underlying LLLT induced biochemical variations.

\section{Discussion}

Confocal Raman imaging provides a powerful tool to characterize the pathological course of spinal cord injuries and the variance in biochemical constituents after its LLLT treatment. Multivariate analysis presents the entire hyperspectral information of the sample in an unambiguous and uncorrelated manner [54]. Once clusters were formed in both the SCI and LLLT groups, some minute-and often important-information that are difficult to observe using univariate methods can also be highlighted in the corresponding average spectra, which were displayed on the right of the separated hierarchical trees in Fig. 3A and 3B. For instance, an overlapping Raman features around $850 \mathrm{~cm}^{-1}$ could be attributed to the single band stretching vibrations for the amino acids and polysaccharides [40, 50]. KCA succeeded in differentiating the tissue structures between unharmed white matter, tissue neighboring the injury site, glial scar, and cavity. Brown cluster in Fig. 4 (corresponding to unharmed white matter) has a hallmark with intense lipid bands at 1300, 1445, and 1668 $\mathrm{cm}^{-1}$. However, the other lipid band [v(c-c) stretching at $\left.1064 \mathrm{~cm}^{-1}\right]$ was overlapped with glucose $\left[\mathrm{v}(\mathrm{C}-\mathrm{OH})\right.$ stretching at $\left.1071 \mathrm{~cm}^{-1}\right]$. The spectra of Red cluster in Fig. 4 presents features which are distinctive of CSPG aggregation, such as a spectral bump around the $510 \mathrm{~cm}^{-1}$, the Amide I bands at $1630 \mathrm{~cm}^{-1}$, and the glucose derivatives band at $1137 \mathrm{~cm}^{-1}$.

Between the areas of brown cluster and red cluster in Fig. 4, blue cluster represents a contact region of unharmed white matter and glial scar, exhibiting a similar spectral feature of lipid (1300, 1445, and $1668 \mathrm{~cm}^{-1}$ ) and non-lipid Raman features (510, 850, and 1071 $\mathrm{cm}^{-1}$ ). The last cluster (in green) showed little spectral contribution, thus indicating (and localizing) cavity formation after the spinal cord injury. While the average spectra in Fig. $4 \mathrm{~A}$ and $4 \mathrm{~B}$ already exhibited considerable evidence that laser irradiation did result in the 


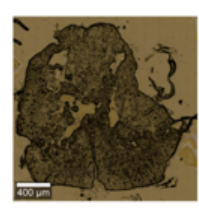

(a)

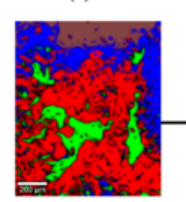

(b)

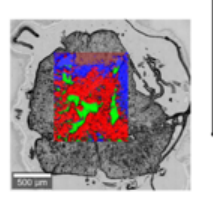

(c)

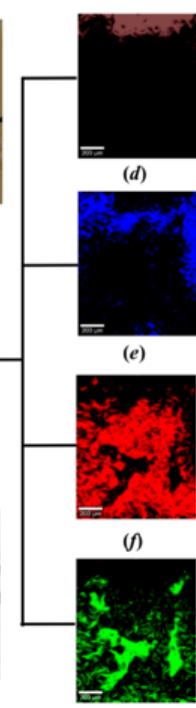

(

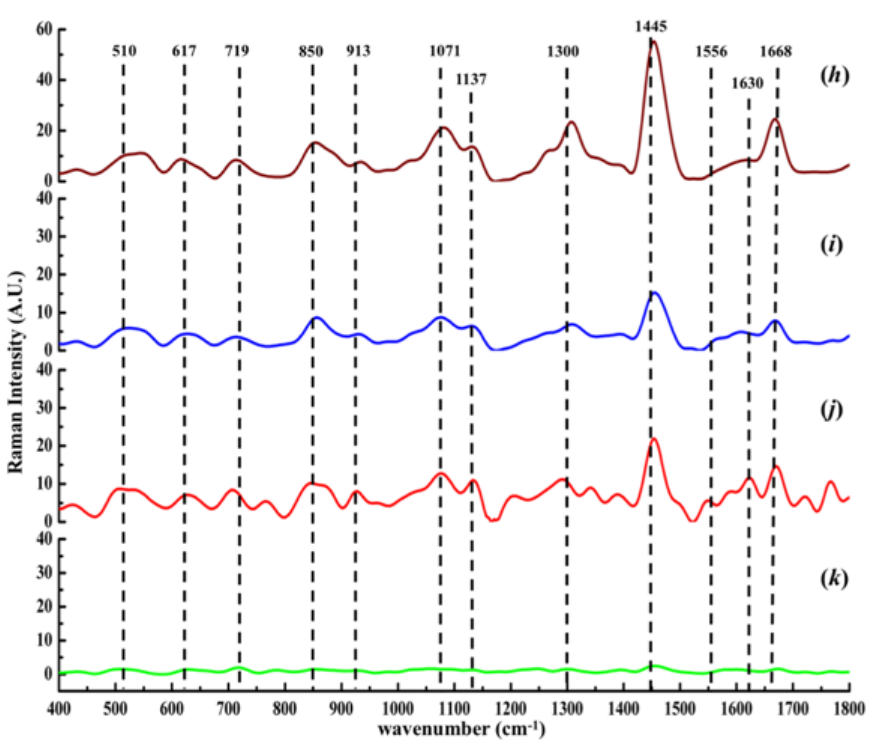

(A)

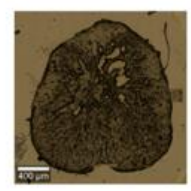

(a)

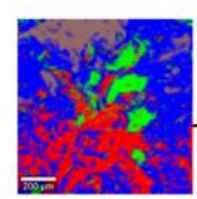

(b)

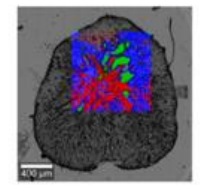

(c)

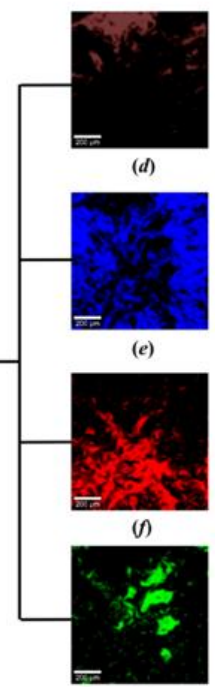

(g)

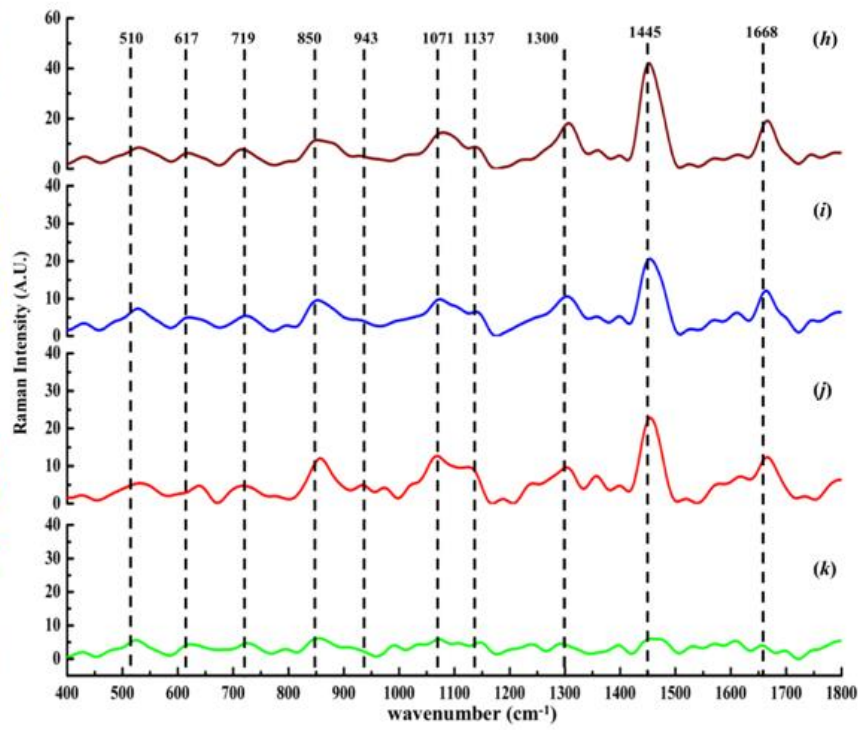

(B)

Fig. 4. K-mean cluster analysis of the acquired Raman dataset from14 DPI (A) and 14 DLT groups (B) using four clusters. Spectra (32000) were obtained at a resolution of $5 \mu \mathrm{m}$ in 14 DPI group; spectra (40000) were obtained at a resolution of $5 \mu \mathrm{m}$ in 14 DLT group. In both groups, image (a) exhibits the microphotograph of a transversal section spinal cord tissue in $2 \times 2 \mathrm{~mm}^{2}$ with $400 \mu \mathrm{m}$ scale bar; image (b) displays the root of a pseudo-hierarchical cluster tree with $200 \mu \mathrm{m}$ scale bar; (c) is the transformation image between (a) and (b) with $400 \mu \mathrm{m}$ scale bar. In each sub-cluster, brown cluster (d) consists of the spectra obtained at the edge of the sampling area where healthy white matter located; blue cluster (e) corresponds with healthy grey matter or area around the injury site; red cluster (f) represents the region with lower lipid content and higher CSPGs content inside the lesion, which can be identified as glial scar structures; green cluster (g) indicates the area where the demyelination process occurred and cavities were generated. The mean spectrum of each sub-clusters is plotted to march their classification in the pseudo-hierarchical cluster tree, which are listed from $(\mathrm{h})$ to $(\mathrm{k})$. 
Fig. 5. Results of the quantitative analysis of the fractional area occupied by each cluster relative to the whole sampled SCI area, based on KCA in Fig. 4. The values are presented as mean \pm standard error of the mean ( $\mathrm{n}=6$ in each group). Asterisks indicate levels of significance, ${ }^{*} \mathrm{P}<0.05,{ }^{* *} \mathrm{P}<0.01$.
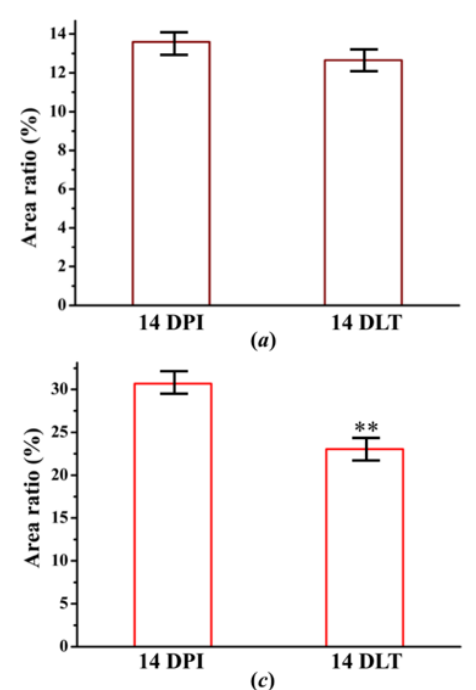

(c)
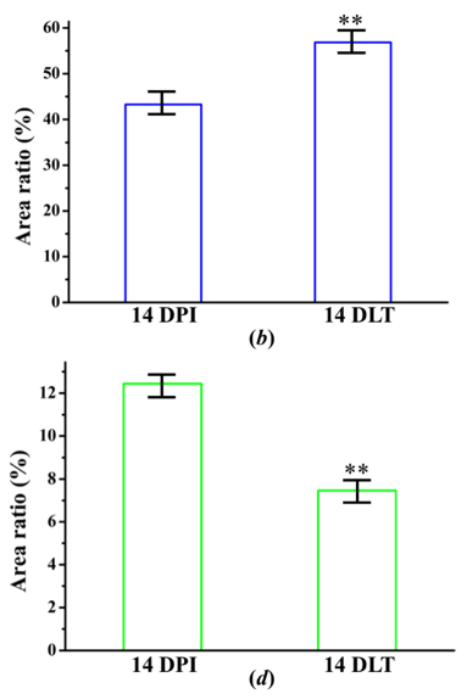

constitution variance conducive to tissue regeneration and recovery after spinal cord injury, an investigation of the morphological changes induced by laser therapy leads to even more obvious conclusions shown in Fig. 5. Altogether, KCA yields a description that is consistent with the ones derived from the previous spectra analysis method: low-level laser irradiation facilitates tissue remyelination and suppresses CSPG aggregation by photo-chemical effect, which could be morphologically depicted by the reduced area of glial scar and cavity.

A PCA was performed to test the classification of spectra as either "SCI" (spectrum measured from 14 DPI tissue) or "treated" (spectrum measured from 14 DLT tissue). Although PCA does not provide an answer for what the physical meaning of each PC is, both the loading spectra and image in Fig. 6 can provide some subtle differences related to the characteristic vibrational frequencies with a dominant contribution in the tissue structures.

Fig. 6A shows that in the PC1 plot (glial scar) the most pronounced changes appear in the CSPG aggregation bands around 510 and $617 \mathrm{~cm}^{-1}$, and in the heme-related band at 1610 $\mathrm{cm}^{-1}$, which confirmed the fact of vascular broken after injury. In contrast, in the PC2 plot (unharmed white matter), the most pronounced changes occur around the lipids bands at 1300,1445 , and $1668 \mathrm{~cm}^{-1}$. Comparatively, in PC3, the negative Raman intensity in the bands of lipids is very remarkable, indicating the tissue region where demyelination happened. In Fig. 6B, after laser treatment, the most prominent bands that determine the coordinates on the PC1 (white matter) - PC2 (glial scar) plot are the bands corresponding to CSPGs $\left(540 \mathrm{~cm}^{-1}\right)$, phosphatidic acid $\left(860 \mathrm{~cm}^{-1}\right)$, lipids $\left(1064,1300,1445\right.$, and $\left.1668 \mathrm{~cm}^{-1}\right)$, glucose derivatives $\left(1137 \mathrm{~cm}^{-1}\right)$, and heme $\left(1589 \mathrm{~cm}^{-1}\right)[55,56]$. The most notable differences relative to the SCI group was that the Raman intensity of the CSPG bands at $540 \mathrm{~cm}^{-1}$ in PC1 decreased very considerably in PC2, and the positive peaks at 860, 1064, 1137, and $1445 \mathrm{~cm}^{-1}$ in PC1 were transformed to negative peaks in PC2. The negative presentation of the glucose derivatives band at $1137 \mathrm{~cm}^{-1}$ might indicate that depolymerized saccharides were eliminated from the extracellular matrix following the LLLT-induced enzymatic reaction. Additionally, the hemerelated Raman band at $1589 \mathrm{~cm}^{-1}$ showed a distinctly positive value in both the PC1 and PC2 plots, which could be correlated to revascularization after laser therapy.

The data from the current study demonstrates that $810 \mathrm{~nm}$ continuous laser, at a dosage of $1500 \mathrm{~J} / \mathrm{cm}^{2}$ significantly suppresses the formation of glial scar and cavity and improves axonal regrowth. Besides that, the obtained Raman spectra features could also be used for interpreting the cellular mechanisms of the SCI pathological progress and its LLLT treatment. Several extracellular matrix (ECM) molecules have been identified as potent inhibitors of neurite outgrowth in vitro and are believed to limit axonal growth after spinal cord injury [57]. The contused lesions in the rats after two weeks showed that the neuron-glial antigen 2 (NG-2) protein-also known as chondroitin sulfate proteoglycan 4 or melanoma-associated chondroitin sulfate proteoglycan - is highly up-regulated and may be 


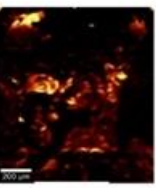

PC3

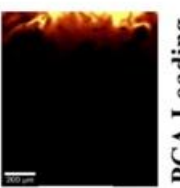

PC2

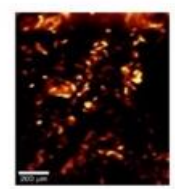

PC1

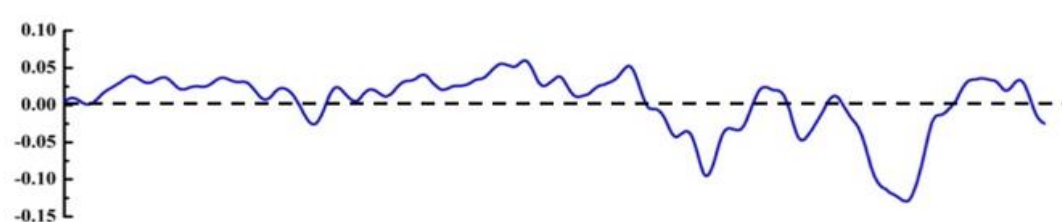

\section{递}
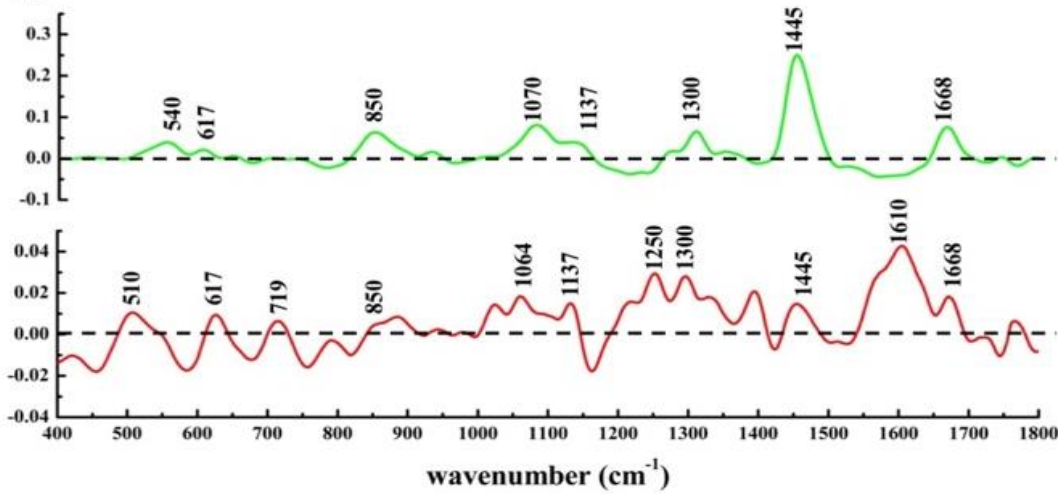

(A)
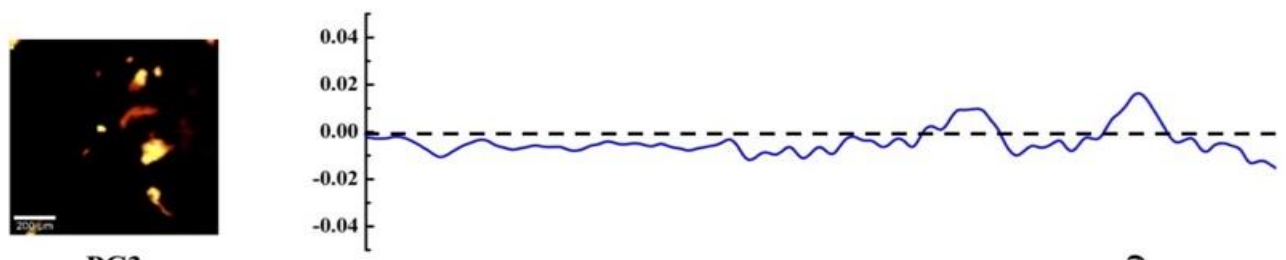

PC3

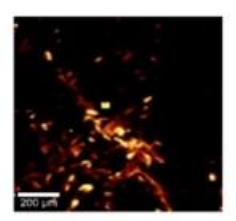

PC2

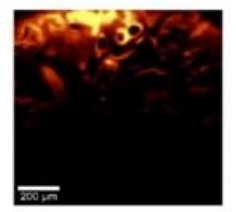

PC1
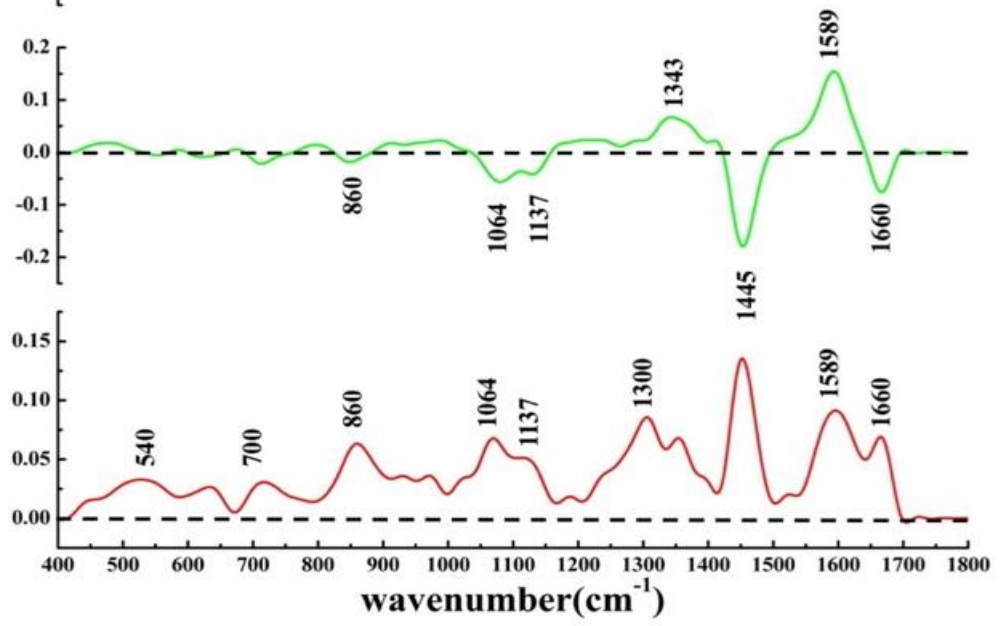

(B)

Fig. 6. Loading spectra plots and images for the first three PCs resulting from PCA of the processed Raman spectra of 14 DPI (A) and 14 DLT group (B). The spatial distribution on the sample of the feature spectra corresponding to each PC is shown on the left. The major bands are labeled with the wavenumber value.

a major component of the inhibitory class of ECM molecules expressed at the SCI sites, which could be depicted by the intensity variations of $510 \mathrm{~cm}^{-1}$ Raman peaks [44], shown in Fig. 3a. As depicted in this figure, based on the redox properties alteration hypothesis [58], the alteration of the mitochondrial metabolism and activation of the respiratory chain by laser illumination increased the production of superoxide anions $\mathrm{O}_{2}^{-}$, which then triggered the 


\section{Cellular Physiology

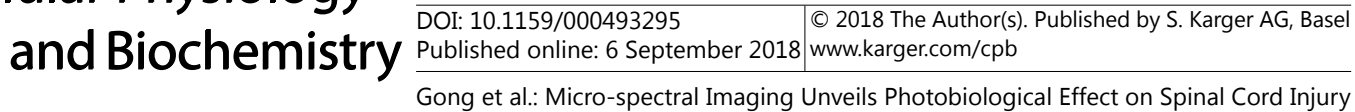

enzymatic degradation of CSPGs by removing the GAG side chains of molecules for improving axonal regeneration, sprouting, and functional recovery. The infusion or overexpression of superoxide dismutase resulted also in the prevention of motor neuron death and improved motor function after SCI.

A known beneficial effect of LLLT on wound healing can be explained by considering several basic biological mechanisms including the induction of expression cytokines and growth factors responsible for the many phases of wound healing [20-22]. In the case of injury cord recovery, the tumor necrosis factor-alpha (TNF- $\alpha$ ), which is the best-known member of the superfamily of cytokines that can cause cell death, possesses inflammatory properties and the ability of inducing apoptosis [59]. Meanwhile, interleukin-6 (IL-6) acts as a pro-inflammatory cytokine and serves as a factor strongly inducing the differentiation of neural stem cells into astrocytes. One of the TNF- $\alpha$ featured Raman peaks is attributed to the ring breathing modes in the DNA/RNA bases at $785 \mathrm{~cm}^{-1}$, whereas one of the IL- 6 featured Raman peaks (centered around $1653 \mathrm{~cm}^{-1}$ ) is attributed to Amide I vibrations of the peptide backbone of proteins $[59,60]$.

\section{Conclusion}

We demonstrated that CRMI, supplemented with multivariate analysis techniques, provides insights into the pathobiological basis of the spinal cord contusion injury. Based on this approach, specific spectral features could be to correlate with biochemical changes triggered by the $810 \mathrm{~nm}, 500 \mathrm{~mW} / \mathrm{cm}^{2}$, low-level laser therapy. The obtained results illustrated the proven pathological course of SCI, including demyelination, CSPG aggregation, apoptosis, and other biological events. Furthermore, the therapeutic effect of LLLT on SCI could be easily discerned and interpreted by investigating the spectral variations on CSPGs, phosphatidic acid, cholesterol, and lipids constituents. The observed variations semiquantitatively confirmed the inhibitory tissue response to remyelination by suppressing CSPG expression after laser treatment, as well as the morphological changes of the tissue structure. Overall, it presents an applicable approach not only for in vitro studies, but also for in vivo monitoring of the pathobiological events associated with SCI from an RS perspective. It also constitutes a solid foundation for our real-time spectroscopic investigation of the biochemical responses to the LLLT treatment for consolidating the SCI therapeutic effect.

\section{Acknowledgements}

This work was supported by the youth programs of Natural Science Foundation of China (No. 11404258, 81572151), the Natural Science Research Foundation of Shaanxi Province (No. 2018JM6033), Key Scientific Research Project of Education Department of Shaanxi, China (No.15JS102), Major Fundamental Research Program of Shaanxi Province, China (No.2016ZDJC-15), and Innovative Team Foundation of Shaanxi province (S2018ZC-TD-0061). This wok was also supported by the outstanding youth scholar project of Northwest University, Shaanxi, China.

\section{Disclosure Statement}

The authors declare that no conflict of interest exist.

\section{References}

\footnotetext{
1 Cadotte DW, Fehlings MG: Spinal Cord Injury: A Systematic Review of Current Treatment Options. Clin Orthop Relat R 2011;469:732.

-2 Young W: Secondary injury mechanisms in acute spinal cord injury. J Emerg Med 1993;11 Suppl 1:13.

-3 Cheng C, Li X, Gao S, Niu S, Chen M, Qin J, Guo Z, Zhao J, Shen A: Expression of CAPON after spinal cord injury in rats. J Mol Neurosci 2008;34:109-119.
} 


\section{Cellular Physiology Cell Physiol Biochem 2018;49:1168-1183 and Biochemistry \begin{tabular}{l|l} 
DOI: 10.1159/000493295 & (c) 2018 The Author(s). Published by S. Karger AG, Basel \\
www.karger.com/cpb
\end{tabular}

4 Tator CH, Fehlings MG: Review of the secondary injury theory of acute spinal cord trauma with emphasis on vascular mechanisms. J Neurosurg 1991;75:15-26.

5 Byrnes KR, Waynant RW, Ilev IK, Wu X, Bama L, Smith K, Heckert R, Gerst H, Anders JJ: Light promotes regeneration and functional recovery and alters the immune response after spinal cord injury. Laser Surg Med 2005;36:171.

6 Liu D, Hua J, Dong QR, Sun YM, Gan MF, Shen YX, Fan ZH, Zhang P: X-ray therapy promotes structural regeneration after spinal cord injury in a rat model. J Orthop Surg Res 2016;11:1-5.

-7 Zeman RJ, Feng Y, Peng H, Visintainer PF, Moorthy CR, Couldwell WT, Etlinger JD: X-irradiation of the Contusion Site Improves Locomotor and Histological Outcomes in Spinal Cord-Injured Rats. Exp Neurol 2001;172:228-234.

8 Schwab ME: Myelin-associated inhibitors of neurite growth and regeneration in the CNS. Trends Neurosci 1990;13:452-456.

-9 Bregman BS, Kunkelbagden E, Schnell L, Dai HN, Gao D, Schwab MEZ: Recovery from spinal cord injury mediated by antibodies to neurite growth inhibitors. Nature 1995;378:498-501.

10 Merkler D, Metz GA, Raineteau O, Dietz V, Schwab ME, Fouad K: Locomotor recovery in spinal cord-injured rats treated with an antibody neutralizing the myelin-associated neurite growth inhibitor Nogo-A. J Neurosci 2001;21:3665-3673.

11 Houweling DA, Lankhorst AJ, Gispen WH, Bär PR, Joosten EAJ: Collagen containing neurotrophin-3 (NT-3) attracts regrowing injured corticospinal axons in the adult rat spinal cord and promotes partial functional recovery. Exp Neurol 1998;153:49-59.

12 Houweling DA, Van Asseldonk JTH, Lankhorst AJ, Hamers FPT, Martin D, Bar PR, Joosten EAJ: Local application of collagen containing brain-derived neurotrophic factor decreases the loss of function after spinal cord injury in the adult rat. Neurosci Lett 1998;251:193-196.

13 Cheng H, Cao Y, Olson L: Spinal cord repair in adult paraplegic rats: partial restoration of hind limb function. Science 1996;273:510.

14 Li Y, Raisman G: Schwann cells induce sprouting in motor and sensory axons in the adult rat spinal cord. J Neurosci 1994;14:4050-4063.

15 Silva NA, Sousa N, Rui LR, Salgado AJ: From basics to clinical: A comprehensive review on spinal cord injury. Prog Neurobiol 2014;114:25.

-16 Kabu S, Gao Y, Kwon BK, Labhasetwar V: Drug delivery, cell-based therapies, and tissue engineering approaches for spinal cord injury. J Control Release 2015;219:141-154.

17 William Posten MD, Wrone DA, FRCPC JSDM, Arndt KA, Sirunya Silapunt MD, Murad Alam MD: Low-level laser therapy for wound healing: mechanism and efficacy. Dermatol Surg 2005;31:334.

18 Chow RT, Johnson MI, Lopes-Martins RA, Bjordal JM: Efficacy of low-level laser therapy in the management of neck pain: a systematic review and meta-analysis of randomised placebo or active-treatment controlled trials. Lancet 2009;374:1897-1908.

19 Hamblin MR, Demidova TN: Mechanisms of low level light therapy. Proc SPIE- The International Society for Optical Engineering 2006;6140:1-12.

-20 Chung H, Dai T, Sharma SK, Huang YY, Carroll JD, Hamblin MR: The nuts and bolts of low-level laser (light) therapy. Ann Biomed Eng 2012;40:516-533.

21 Oron A, Oron U, Chen J, Eilam A, Zhang C, Sadeh M, Lampl Y, Streeter J, Detaboada L, Chopp M: Low-level laser therapy applied transcranially to rats after induction of stroke significantly reduces long-term neurological deficits. Stroke 2006;37:2620-2624.

22 Oron A, Oron U, Streeter J, De TL, Alexandrovich A, Trembovler V, Shohami E: Low-level laser therapy applied transcranially to mice following traumatic brain injury significantly reduces long-term neurological deficits. J Neurotraum 2007;24:651.

-23 Stadler I, Evans R, Kolb B, Naim JO, Narayan V, Buehner N, Lanzafame RJ: In vitro effects of low-level laser irradiation at $660 \mathrm{~nm}$ on peripheral blood lymphocytes. Laser Surg Med 2000;27:255.

24 Agaiby AD, Ghali LR, Wilson R, Dyson M: Laser modulation of angiogenic factor production by T-lymphocytes. Laser Surg Med 2000;26:357.

25 Demidovarice TN, Salomatina EV, Yaroslavsky AN, Herman IM, Hamblin MR: Low-level light stimulates excisional wound healing in mice. Laser Surg Med 2007;39:706.

-26 Piva JA, Abreu EM, Silva VS, Nicolau RA: Effect of low-level laser therapy on the initial stages of tissue repair: basic principles. An Bras Derrmatol 2011;86:947-954

27 Wu X, Dmitriev AE, Cardoso MJ, Viers-Costello AG, Borke RC, Streeter J, Anders JJ: 810 nm Wavelength light: An effective therapy for transected or contused rat spinal cord. Laser Surg Med 2009;41:36-41.

28 Moore P, Ridgway TD, Higbee RG, Howard EW, Lucroy MD: Effect of wavelength on low-intensity laser irradiation-stimulated cell proliferation in vitro. Laser Surg Med 2005;36:8-12. 


\section{Cellular Physiology Cell Physiol Biochem 2018;49:1168-1183

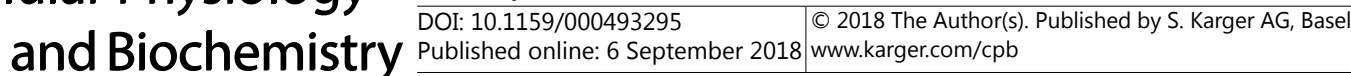

-29 Von Leden RE, Cooney SJ, Ferrara TM, Zhao Y, Dalgard CL, Anders JJ, Byrnes KR: 808nm wavelength light induces a dose-dependent alteration in microglial polarization and resultant microglial induced neurite growth. Lasers Surg Med 2013;45:253-263.

-30 Ando T, Sato S, Kobayashi H, Nawashiro H, Ashida H, Hamblin M, Obara M: Low-level laser therapy for spinal cord injury in rats: effects of polarization. J Biomed Opt 2013;18:98002.

-31 Rochkind S, Shahar A, Alon M, Nevo Z: Transplantation of embryonal spinal cord nerve cells cultured on biodegradable microcarriers followed by low power laser irradiation for the treatment of traumatic paraplegia in rats. Neurol Res 2002;24:355-360.

32 Krafft C: Raman Spectroscopy and Microscopy of Cells and Tissues; in Springer, Encyclopedia of Biophysics, Heidelberg, 2013, 2178.

33 Resau JH: Book Review: Handbook of Biological Confocal Microscopy. Vet Pathol 2008; 45:111-112.

-34 Mueller, Joerg, Ibach, Wolfram, Weishaupt, Klaus, Hollricher, Olaf: Confocal Raman Microscopy. Microsc Microanal 2009;15(Suppl 2):1084-1085.

35 Klein K, Gigler AM, Aschenbrenner T, Monetti R, Bunk W, Jamitzky F, Morfill G, Stark RW, Schlegel J: Labelfree live-cell imaging with confocal Raman microscopy. Biophys J 2012;102:360-368.

-36 Saxena T, Deng B, Stelzner D, Hasenwinkel J, Chaiken J: Raman spectroscopic investigation of spinal cord injury in a rat model. J Biomed Opt 2011;16:027003.

37 Wang S, Liang Z, Gong Y, Yin Y, Wang K, He Q Wang Z, Bai J: Confocal raman microspectral imaging of ex vivo human spinal cord tissue. J Photoch Photobio B 2016;163:177-184.

38 Gong Y, Liang Z, Yin Y, Song J, Hu X, Wang K, He Q, Wang Z, Bai J, Wang S: Interpreting the biochemical specificity of mouse spinal cord by confocal raman microspectral imaging. J Innov Opt Heal Sci 2017;10.

39 Ruberto SM: Raman spectroscopic investigation of chondroitinase ABC treatment after spinal cord injury in an organotypic model. Dissertations \& Theses - Gradworks. 2013.

-40 Galli R, Uckermann O, Winterhalder MJ, Sitocificici KH, Geiger KD, Koch E, Schackert G, Zumbusch A, Steiner G, Kirsch M: Vibrational spectroscopic imaging and multiphoton microscopy of spinal cord injury. Anal Chem 2012;84:8707.

41 Tamosaityte S, Galli R, Uckermann O, Sitocificici KH, Later R, Beiermeister R, Doberenz F, Gelinsky M, Leipnitz E, Schackert G: Biochemical monitoring of spinal cord injury by FT-IR spectroscopy-effects of therapeutic alginate implant in rat models. Plos One 2016;10:e0142660.

42 Shi Y, Zhang D, Huff TB, Wang X, Shi R, Xu XM, Cheng JX: Longitudinal in vivo coherent anti-Stokes Raman scattering imaging of demyelination and remyelination in injured spinal cord. J Biomed Opt 2011;16:106012.

-43 Hausmann ON: Post-traumatic inflammation following spinal cord injury. Spinal Cord 2003;41:369-378.

44 Saxena T: Characterization of the glial scar using Raman spectroscopy, microindentation, and immunohistochemistry. Dissertations \& Theses - Gradworks. 2010.

45 Czamara K, Majzner K, Pacia MZ, Kochan K, Kaczor A, Baranska M: Raman spectroscopy of lipids: a review. J Raman Spectrosc 2015;46:4-20.

46 Sandy JD, Flannery CR, Neame PJ, Lohmander LS: The structure of aggrecan fragments in human synovial fluid. Evidence for the involvement in osteoarthritis of a novel proteinase which cleaves the Glu 373-Ala 374 bond of the interglobular domain. Arthritis Rheumatol 1992;36:1512-1516.

47 Nave KA, Werner HB: Myelination of the nervous system: mechanisms and functions. Annu Rev Cell Dev Bi 2014;30:503-533.

-48 Sato K, Ohmae E, Senoo E, Mase T, Tohyama K, Fujimoto E, Mizoguchi A, Ide C: Remyelination in the rat dorsal funiculus following demyelination by laser irradiation. Neurosci Res 1997;28:325.

49 Carmona P, Ramos JM, Cózar MD, Monreal J: Conformational features of lipids and proteins in myelin membranes using Raman and infrared spectroscopy. J Raman Spectrosc 1987;18:473-476.

50 Movasaghi Z, Rehman S, Rehman DIU: Raman spectroscopy of biological tissues. Appl Spectrosc Rev 2007;42(5):493-541.

51 Fawcett JW, Schwab ME, Montani L, Brazda N, Müller HW: Chapter 31 - Defeating inhibition of regeneration by scar and myelin components; in Handbook of Clinical Neurology, Elsevier Health Sciences, Cambridge, 2012, pp 503.

$>52$ Premasiri WR, Lee JC, Ziegler LD: Surface-enhanced Raman scattering of whole human blood, blood plasma, and red blood cells: cellular processes and bioanalytical sensing. J Phys Chem B 2012;116:93769386.

53 Bonifacio A, Beleites C, Vittur F, Marsich E, Semeraro S, Paoletti S, Sergo V: Chemical imaging of articular cartilage sections with Raman mapping, employing uni- and multi-variate methods for data analysis. Analyst 2010;135:3193-3204. 


\section{Cellular Physiology Cell Physiol Biochem 2018;49:1168-1183 \begin{tabular}{ll|l} 
and Biochemistry 2018 The Author(s). Published by S. Karger AG, Basel \\
\cline { 2 - 2 } Published online: 6 September 2018 www.karger.com/cpb
\end{tabular}

54 Parthasarathy R, Thiagarajan G, Yao X, Wang YP, Spencer P, Wang Y: Application of Multivariate Spectral Analyses in Micro-Raman Imaging to Unveil Structural/Chemical Features of the Adhesive/Dentin Interface. J Biomed Opt 1900;13:014020.

55 Marzec KM, Rygula A, Wood BR, Chlopicki S, Baranska M: High-resolution Raman imaging reveals spatial location of heme oxidation sites in single red blood cells of dried smears. J Raman Spectrosc 2015;46:7683.

56 Lin J, Lin J, Huang Z, Lu P, Wang J, Wang X, Chen R: Raman spectroscopy of human hemoglobin for diabetes detection. J Innov Opt Heal Sci 2014;7:1350051.

57 Jones LL, Yu Y, Stallcup WB, Tuszynski MH: NG2 Is a major chondroitin sulfate proteoglycan produced after spinal cord injury and is expressed by macrophages and oligodendrocyte progenitors. J Neurosci 2002;22:2792.

-58 Lubart R, Eichler M, Lavi R, Friedman H, Shainberg A: Low-energy laser irradiation promotes cellular redox activity. Photomed Laser Surg 2005;23:3.

59 Czamara K, Majzner K, Selmi A, Baranska M, Ozaki Y, Kaczor A: Unsaturated lipid bodies as a hallmark of inflammation studied by Raman 2D and 3D microscopy. Sci Rep 2017;7:40889.

60 Xiong Y, Ye A, Wen C, Zhang Y: Investigation on activating individual living monocytic U937 cell by interleukin-6 using Raman tweezers. Chin Opt Lett 2010;8:1015-1018.

61 E. Koch, G. Schackert, G. Steiner, K. H. Sitocificici, M. Koch, M. Kirsch, M. Gelinsky, O; in Uckermann, R. Later and R. Galli (eds): Raman-based imaging uncovers the effects of alginate hydrogel implants in spinal cord injury. Proc of SPIE-OSA, Munich, Germany, 21-25 June 2015, Vol. 9536, 95360Y.

-62 Krafft C, Neudert L, Simat T, Salzer R: Near infrared Raman spectra of human brain lipids. Spectrochim Acta A 2005;61:1529.

63 Kochan K, Marzec KM, Chruszczlipska K, Jasztal A, Maslak E, Musiolik H, Chlopicki S, Baranska M: Pathological changes in the biochemical profile of the liver in atherosclerosis and diabetes assessed by Raman spectroscopy. Analyst 2013;138:3885-3890. 